Endocrinology

\section{Precocious puberty: a parent's perspective}

\section{E O'Sullivan, M O'Sullivan}

\section{How bad can it get?}

W e are writing as parents of a young girl who "suffers" from precocious puberty and we use the word suffers without reservation despite the fact that:

- Puberty is a normal process

- No underlying cause triggering her puberty has been determined.

Our daughter started to show physical signs of development, for example, breast development combined with pubic hair, at $6 \frac{1}{2}$ years, and within a year experienced her first period. We were devastated by this event, as our local general practitioner had told us that there was nothing to worry about, and that we were imagining and exaggerating things. Our ongoing concerns for an explanation and regular visits to the surgery were seen as pushy and demanding. Surely confronted with this period, an obvious sign of female maturity arriving very early, we would get help and support. Regrettably, it didn't get any easier.

The good news was that the general paediatrician to whom we were first referred was really helpful. He confirmed that he had rarely encountered the condition before but would organise particular tests to discount any underlying causes for this early growth, such as cranial or ovarian tumours. Our shock with these possibilities was diminished by the speed of his tests and his effectiveness in communicating to the three of us as results came in. Fortunately no underlying cause was identified and we were referred to a paediatric endocrinologist. Confusion was about to reign again.

The specialist recommended that our daughter, who has "central precocious puberty", should receive analogue treatment (with gonadotrophin releasing hormone analogue) to suppress her accelerated development and enhance her height potential. Growing up early, he explains, will result in compromised final height. Before commencing this treatment we seek a second opinion from another paediatric endocrinologist. We find that an insufficient range of tests have been organised to discount any underlying cause. We need to reconfirm the diagnosis before starting treatment with such an analogue. The treatment may now be irrelevant, but in any case it doesn't, in his view, enhance final height attainment.

$$
\begin{gathered}
\text { "Now the shock is turning } \\
\text { to dismay, anger, and } \\
\text { frustration" }
\end{gathered}
$$

Eighteen months of consultations and divided opinions pass before we can commence treatment-during which our daughter is continuing to develop. Monthly periods, moodiness, greasy skin, acne, but most critically accelerated bone maturation, reducing the scope for further height attainment. At last, our third specialist consultant agrees to organise the treatment and we proceed down this new route.

Our daughter's periods stop, her skin improves, moodiness reduces, and our child comes back to us. She even prefers an injection to a period and her confidence with her peers returns to previous levels. She is normal again! But to what end and at what cost? Our daughter finished her 12 months treatment early this year and her recent final bone age test now confirms that "too little was done too late". So what is the net effect after three and a half years? I will leave you to imagine what we think of most of the medical profession we have encountered.

During this time we have been aided by the Child Growth Foundation which conducted a major survey of parents with children affected by precocious puberty. The results showed that only $45 \%$ of paediatricians' and $83 \%$ of paediatric endocrinologists' ratings by parents were in an "adequate" to "very good" range. In other words, the above story is not at all atypical.

The key issues for the profession to address, deriving from the survey, are:

- General practitioners should not disregard diagnostic symptoms and should listen to parents. They should not belittle the condition or its concerns.

- The roles of the paediatricians and the paediatric endocrinologists need to be differentiated to avoid delay and to improve efficiency.
- The specialists need to communicate effectively and declare in what situations the "analogue" will or will not be given. Does it or does it not enhance growth generally or specifically?

- How can the profession help the child and the parents in dealing with difficult situations at school and socially?

- Given the devastating effect on the parents and the child, how can the profession assist them with proactive advice and assistance?

The answer to the last question is currently being worked on at the Child Growth Foundation. Best Practice Guidelines are being prepared to assist children and parents in understanding the range of issues that these conditions surface. They are also aimed at the medical profession to assist them in helping patients and their families. A copy of the full survey is available on the ADC website. The Best Practice Guidelines are available from cgflondon@aol.com.

This article was produced to challenge the profession to prevent this type of situation recurring. We know that precocious puberty is a rare condition, is not life threatening, and the NHS always needs more resources-but surely we can't let these issues go unanswered?

Arch Dis Child 2002;86:320-321

\section{Authors' affiliations} E O'Sullivan, M O'Sullivan, Romford, Essex, UK

Correspondence to: MrE O'Sullivan, 176 Brian Road, Chadwell Heath, Romford, Essex

RM6 5BS, UK; osullivanassoc@eircom.net

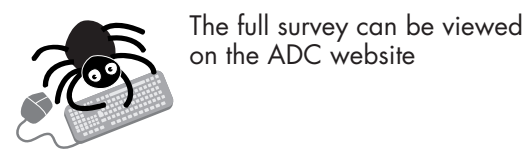

COMMENTARY

7 his article shows the plight of parents with a child who has precocious puberty-girls less than 8 years, boys below 9 years. One is left in no doubt that this is an alarming and frightening situation that can cause difficult initial visits to doctors because of its relatively low frequency in such a florid form and also because of the issue of whether there is something sinister or serious as an underlying cause. In practice, even in girls of 6 years, it is unusual to find a brain or ovarian tumour when there is a normal sequence of puberty development, albeit accelerated. It has been argued that early sexual 
development is becoming more common in recent years, but the evidence for this is poor, as shown by Viner. ${ }^{1}$

Most general paediatricians confronted with a young child showing signs of puberty would initiate early investigations, such as checking gonadotrophin and oestradiol levels, thyroid function, $\beta$ HCG, prolactin, and a bone age and a pelvic ultrasound. Depending on local facilities they may well organise a magnetic resonance imaging (MRI) scan of the mid brain and pituitary area. They would determine whether the sequence of puberty development was normal, plot growth carefully, exclude any signs of raised intracranial pressure, and look for any abnormal pigmentation to suggest McCune-Albright syndrome. It is likely that a second opinion will be sought from a paediatric endocrinologist. One of the key things during this difficult time for the parents is effective communication of what is going on, and what investigations are to be undertaken and why.

The paediatric endocrinologist should be in a position to continue the discussions initiated by the general paediatrician, decide whether further tests are needed, and will no doubt discuss the issue of blocking treatment. Unfortunately, as shown at a national meeting on premature sexual maturation organised by the Child Growth Foundation in London in 2000, there was no strong consensus view among endocrinologists about how extensive investigations should be and how aggressive analogue blocking treatment should be with gonadotrophin releasing hormone analogues. Some endocrinologists argue that MRI brain and pituitary scanning has a very low pick up rate in girls unless very young, and there was disagreement about whether this test should be undertaken at $7-8$ years, although nearly all agree that at $6^{1 / 2}$ years girls should have an MRI scan, as well as all boys below 9 years.

Views about whether children should have blocking treatment were more variable, with quite a wide range of opinions; it was pointed out that there is no strong evidence base on which to judge these decisions. The issue of which patients to treat with analogue treatment is discussed by Brook ${ }^{2}$ in his textbook on paediatric endocrinology; he favours treatment in younger patients. His view is that the question of treatment or no treatment should be based on assessment of growth prognosis and the child's psychology maturity. The psychological aspects of the condition on a young child and their family are easy to underestimate by professionals

If treatment is to be given, there is now another controversial issue of whether a standard intramuscular injection on a 3-4 week basis should be given, or whether a slow release preparation should be given every 2-3 months - the efficacy of the latter was shown by Patterson and colleagues. ${ }^{3}$ In the past the issue of advanced bone age was given as a strong reason for starting treatment to prevent premature fusion of epiphyses and short final height stature, but the evidence for this in children with later onset is inconclusive. The parents at this meeting felt it frustrating and difficult to accept that doctors from different teaching hospitals had divergent views. With this background the issue of communicating well with parents is crucial.

In the case of this young girl the parents mentioned that a second paediatric endocrinology opinion was sought. It is not clear why they felt this was necessary, but it did result in delay of treatment which was eventually commenced 18 months after onset of periods. The parents state candidly that it doesn't take much to imagine their views of the medical profession. The Child Growth Foundation has a difficult role as it needs to support parents with this frightening condition, give background literature and information, and sometimes give suggestions of where to go for second opinions. There is of course an inherent danger in second or third opinions, as there may be conflicting views which may cause confusion and delay treatment.
The survey carried out by the Child Growth Foundation is helpful:

- General practitioners should certainly refer urgently and listen to parents.

- As discussed, the roles of paediatricians and paediatric endocrinologists need to be distinguished.

- Should analogue treatment be given? Further research is needed to look into the issue of whether it enhances growth potential. Many would agree that the growth argument with premature fusion of the epiphyses has been unintentionally exaggerated in the past.

- The parents ask about help for the child and the parents in dealing with this difficult situation at school and socially; this must be a key role for the Child Growth Foundation. Hopefully most paediatricians would look in the CaF (Contact a Family) directory to look up the support groups in such a situation. Community paediatric nursing teams also have a support role in giving advice at school and at home.

- How can the professionals assist with giving proactive advice and assistance?

Have a look at the full survey by the Child Growth Foundation and their Best Practice Guidelines. Treatment for this rare but devastating condition for parents and children is still somewhat unpredictable. Do write in with your views and comments.

\section{N Mann, Commissioning Editor}

\section{REFERENCES}

1 Viner R. Splitting hairs. Arch Dis Child 2002;86:8-10.

2 Brook CGD. Clinical paediatric endocrinology, 3rd edn. Oxford: Blackwell Science Ltd, 1995:257-62.

3 WF Patterson, E McNeill, S Read, et al. Efficacy of Zoledex LA (goserelin) in the treatment of girls with central precocious or early puberty. Arch Dis Child early puberty. Arch
1998;79:323-7. 